\title{
MOVEMENT OF HEAD AND CENTER OF MASS: JOINT ASSESSMENT
}

\author{
Vasilyev V.S. ${ }^{*}$, Borisov V.I., Syskov A.M. \\ Ural Federal University, Yekaterinburg, Russia \\ *E-mail: vasilyev.v@protonmail.com
}

In this study, a supposition of relation between movements of head and center of mass is made. A case study on small group was carried out. After application of continuous-wavelet transform to acquired signals of head and body movement, it was found that resulting signals contain common frequencies. Further development of described methodology is proposed.

Известно, что тело человека является обратным маятником [1]. В работе проверяется гипотеза о наличии взаимосвязи между движением головы и движением центра масс.

Для проверки этой гипотезы было проведено исследование с участием 10 испытуемых в возрасте $20 \pm 3$ лет. Для снятия сигнала движения центра масс использовалась стабилоплатформа «Стабилан-01»; сигнал движения головы записывался 3-х осевых акселерометром интерфейса мозг-компьютер «Emotiv EPOC+».

Стоя на стабилоплатформе перед экраном монитора, с закрепленным на голове акселерометром, испытуемый проходил через следующие этапы исследования:

1. Фон (3 минуты) - нахождение в естественной позе, отсутствие внешних воздействий;

2. Разминка (40 секунд) - совершение круговых движений и наклонов головой;

3. Тест «Мишень» (5 минут) - на экране появляется изображение мишени и маркер (проекция центра масс на плоскость стабилоплатформы); задача испытуемого - балансируя на платформе, удерживать маркер в центре мишени;

4. Последействие (3 минуты) - как этап Фон.

В ходе этапов сигналы ускорения по осям акселерометра и отклонения центра масс по осям стабилоплатформы записывались для дальнейшего анализа.

Для оценки частотных характеристик сигналов использовалось непрерывное вейвлет-преобразование. Вейвлет Морле был выбран в качестве материнского, как наиболее подходящий для оценки нестационарных сигналов [2].

Пример скейлограмм сигналов ускорения по фронтальной оси акселерометра и смещения центра масс по фронтальной оси стабилоплатформы показан на Рисунке 1 . 

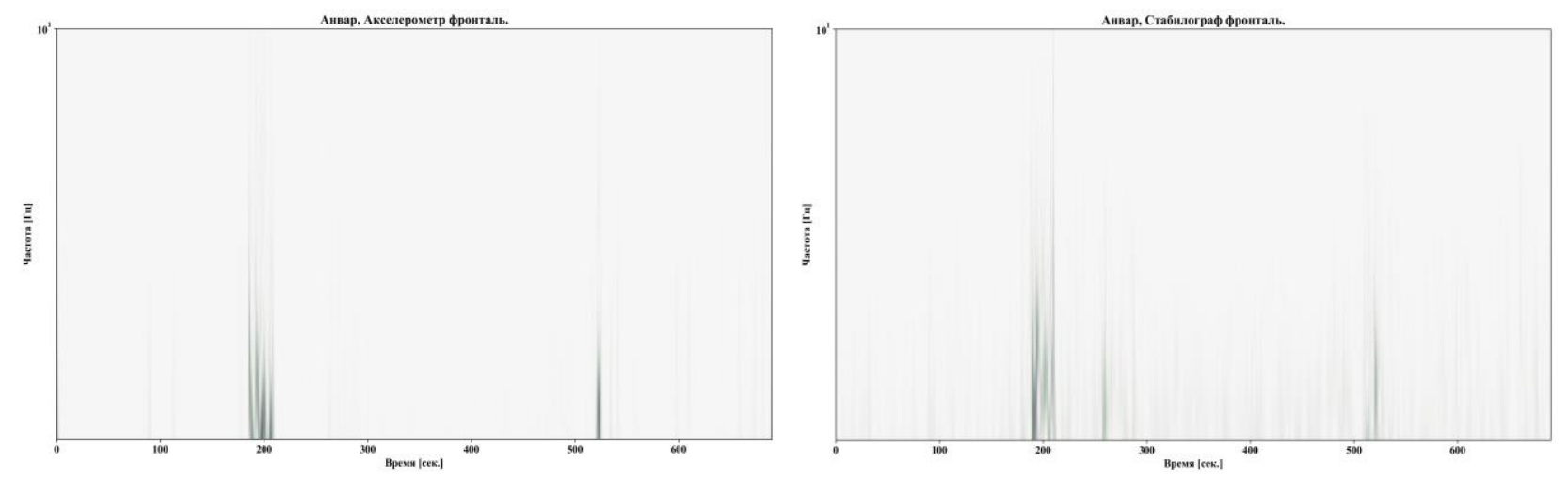

Рис. 1. Вейвлет-скейлограммы сигналов движения головы и центра масс.

Как показано на графиках выше, оба сигнала имеют пики амплитуды в нескольких частотно-временных областях. Явно выражен переход между этапами фона и разминки (180-220 сек.), а так же окончание теста «Мишень» (520 сек.). Это подтверждает исходную гипотезу о наличии взаимосвязи между движениями головы и центра масс.

Для оценки данной методологии необходимо провести дополнительные исследования с большей выборкой испытуемых, с использованием методов нелинейной динамики для оценки контроля равновесия [3].

1. Usachev V.I, Stabilometric parameters, CJSC «RITM» (2011).

2. Rafieea J., Rafieea M.A. et al., Wavelet basis functions in biomedical signal processing, Expert systems with applications, 38, 11 (2011).

3. Collins J.J., De Luca C.J., Upright, correlated random walks: A statistical-biomechanics approach to the human postural control system, CHAOS, 5, 7 (1995). 